\title{
ELABORAÇÃO DA TRILHA INTERPRETATIVA NO MORRO DAS ANDORINHAS: UMA PROPOSTA DE EDUCAÇÃO AMBIENTAL NO PARQUE ESTADUAL DA SERRA DA TIRIRICA, RJ
}

\author{
Mariana Macêdo Barcellos ${ }^{1}$ \\ Stephanie Maia ${ }^{2}$ \\ Camila Meireles ${ }^{2}$ \\ Douglas de Souza Pimentel $^{3}$
}

\section{Resumo}

Os parques são unidades de proteção integral para os quais são previstos a pesquisa, a educação ambiental e o uso turístico. O Parque Estadual da Serra da Tiririca (PESET) que representa uma área natural no contexto urbano está localizado na divisa das cidades de Niterói e Maricá (RJ), possui trilhas que proporcionam a observação de paisagens exuberantes e recebe diariamente centenas de visitantes. No entanto, muitos frequentadores pouco sabem sobre a unidade de conservação. Nesse sentido, a interpretação ambiental pode ser uma ferramenta de educação ambiental, ao permitir que os visitantes desfrutem de novas experiências, novos aprendizados e melhor compreensão dos aspectos socioambientais. $\mathrm{O}$ objetivo do presente trabalho é propor uma trilha interpretativa para o Morro das Andorinhas. A sondagem para a determinação dos pontos interpretativos foi feita durante as atividades do Programa de Educação Ambiental (PEA) realizadas pelo Museu de Arqueologia de Itaipu, com escolas do entorno do Parque. Foram considerados os questionamentos dos alunos, os aspectos físicos, biológicos e paisagísticos relevantes para a interpretação ambiental. Além disso, também foi feita uma caracterização física da trilha, que subsidiara um programa de monitoramento dos impactos da visitação.

Palavras-chave: Trilha interpretativa; PESET; uso público; impactos

\begin{abstract}
The parks are protected areas which provide research, environmental education and tourism use. The Serra da Tiririca State Park of (PESET), that represents a natural area in the urban context, is located on the border of the cities of Niteroi and Marica (RJ). The Park has trails that provide observation of lush landscapes and receives hundreds of daily visitors. However, many regulars know little about it. In this sense, environmental interpretation can be a tool for environmental education, to allow visitors to enjoy new experiences, new learning, and better understanding of the environmental aspects. The aim of this work is to propose an interpretive trail to the Morro das Andorinhas. A survey to determine the points of interpretation was made during the activities of the Environmental Education Program (PEA) conducted by the Archaeology Museum of Itaipu, with schools in the area surrounding the park. We considered the questions of the students, the physical, biological and landscape relevant to the environmental interpretation. In addition, we made a physical characterization of the trail that will subsidize a program to monitor the visitor's impacts.
\end{abstract}

Keywords: Interpretative trail; PESET; public use; impacts

\footnotetext{
${ }^{1}$ Graduanda de Ciências Biológicas da Faculdade de Formação de Professores da Universidade do Estado do Rio de Janeiro (FFP/UERJ) - Integrante do Grupo de Estudos Interdisciplinares do Ambiente (GEIA)

${ }^{2}$ Mestranda do Programa de Pós-Graduação em Ensino de Ciências, Ambiente e Sociedade da FFP/UERJ GEIA

${ }^{3}$ Professor da FFP/UERJ (GEIA) e da Universidade Federal Fluminense. E-mail: douglasgeia@ gmail.com
} 


\section{Introdução}

\section{As Unidades de Conservação}

André Rebouças fez a primeira proposta de criação de Parques Nacionais no Brasil já em 1876. O engenheiro inspirou-se no modelo norte americano, que estabeleceu o conceito de reserva de áreas de grande beleza cênica para a conservação ambiental e usufruto das populações urbanas com fins recreativos e turísticos (PIMENTEL, 2008; TAKAHASHI, 1998). Os principais dispositivos de proteção da natureza nacionais foram estabelecidos a partir de 1934 com o Código Florestal. Segundo Medeiros (2006), essa lei definiu as bases para a proteção territorial de ecossistemas florestais e outras formas de vegetação natural do Brasil, sendo o primeiro instrumento de proteção a definir de forma clara as tipologias de áreas a serem especialmente protegidas. Assim, condições favoráveis para a formalização dos primeiros Parques Nacionais brasileiros foram estabelecidas e o Parque Nacional de Itatiaia foi criado em 1937.

Progressivamente, até o início dos anos 1990, instituiu-se no Brasil uma política de criação de áreas protegidas, porém de forma desarticulada, com diferentes precariedades referentes à sua gestão (MEDEIROS; IRVING; GARAY, 2004). No ano 2000, a aprovação da Lei 9.985/2000, que promulgou o Sistema Nacional de Unidades de Conservação (SNUC), almejava o estabelecimento de um sistema mais integrado para a criação e gerenciamento dessas áreas protegidas, agora chamadas de Unidades de Conservação (UCs) (IRVING, 2006; MACHADO, 2010; MEDEIROS; IRVING; GARAY, 2004).

Existem dois grupos de UCs, de proteção integral e de uso sustentável (BRASIL, 2002) e cada um abrange categorias específicas de manejo. Essas categorias de manejo almejam a regulação do uso de recursos e a ocupação do espaço. Particularmente as do primeiro grupo "representam a aplicação prática da visão de preservação dos processos ecossistêmicos livres da interferência humana" (PIMENTEL; MAGRO, 2011, p. 92). A categoria Parque Nacional se insere no grupo das Unidades de Proteção Integral, estabelecendo como objetivo básico:

[...] a preservação de ecossistemas naturais de grande relevância ecológica e beleza cênica, possibilitando a realização de pesquisas científicas e o desenvolvimento de atividades de educação e interpretação ambiental, de recreação em contato com a natureza e de turismo ecológico (BRASIL, 2002, p. 16).

Assim, uso turístico é previsto para essa categoria de UC. No entanto, o aumento dessas atividades sem planejamento adequado pode causar mais danos do que benefícios aos parques. Nesse sentido, outro objetivo do parque - a educação e a interpretação ambiental - se caracterizam como ferramentas indispensáveis para o manejo desse uso público.

\section{Uso Público nos Parques e a Interpretação Ambiental}

Magro (1999) afirma que o termo uso público pode ser definido como o usufruto gozado pelo público, sendo ele recreacionista, educador, pesquisador ou religioso. O uso de áreas naturais para a recreação intensificou-se principalmente a partir do século XIX, quando, 
em decorrência do crescimento das cidades, a população urbana foi estimulada a frequentar os espaços rurais e selvagens em busca de lazer, esporte e espiritualidade (OLIVEIRA, 2009). Nesse sentido, as trilhas, que anteriormente apenas supriam a necessidade de deslocamento, passaram a ser, elas próprias, uma nova forma de contato com a natureza. (OLIVEIRA; BLOOMFIELD; MAGALHÃES, 1999).

Vasconcellos (2006) assegura que a presença na natureza possibilita:

O entendimento do entorno ecológico, com suas interdependências; o reconhecimento das consequências das ações humanas e das próprias ações sobre este entorno; a busca de formas sustentáveis de viver, através de escolhas conscientes; o envolvimento nos esforços conjuntos para a conservação da natureza (p. 22).

A princípio, o contato do homem com natureza apresenta-se de forma positiva para a conservação do ambiente natural. No entanto, a falta de planejamento de atividades nesse ambiente, desrespeitando as potencialidades e vulnerabilidade do mesmo, pode comprometer a conservação do local (BUENO, 2010; GARCEZ, 2007, p. 2). Impactos são causados no solo, na vegetação e na fauna e representam uma consequência da ação direta da utilização das trilhas. $\mathrm{O}$ aumento da largura da trilha pelo uso intenso também é um fator impactante (ALCANTARA, 2007; ANDRADE; ROCHA, 2008). O lixo é outro exemplo relacionado aos impactos provocados pelo uso público.

No entanto, segundo Lobo e Simões (2009):

“A visitação de lazer, recreativa, contemplativa, ou educativa, quando bem manejada, traz inúmeros benefícios à UC, através da promoção de sua proteção e conservação; benefícios sociais, através da educação ambiental (...)" (p. 9).

Portanto, é imprescindível que a relação entre uso público e meio ambiente seja permeada pela sensibilização ambiental e para tanto, a educação ambiental pode atuar como instrumento de planejamento e como auxiliadora na apreciação dos valores que o ambiente apresenta, estabelecendo as bases para avaliações sobre a reformulação do seu uso, para mitigar os impactos negativos causados pelos visitantes (SILVA; NETO, 2007).

A partir de 1957, o filósofo americano Freeman Tilden contribuiu para a formalização da Interpretação Ambiental em trilhas, através da publicação intitulada "Interpreting Our Heritage" (Interpretando nosso Patrimônio). No livro, Tilden aborda de forma clara e coerente os principais temas da interpretação ambiental com exemplos práticos e de fácil entendimento, fundamentado em suas experiências no Serviço de Parques Nacionais dos Estados Unidos (PROJETO DOCES MATAS, 2002; MENGHINI, 2005).

Vasconcellos (2006) também apresenta os Princípios de Interpretação Ambiental. Em síntese, interpretar significa despertar a curiosidade, construir conceitos, provocar reações nos indivíduos. Esses princípios são considerados básicos para os programas interpretativos, mesmo após as evoluções referentes aos meios e técnicas de comunicação e informação (VASCONCELLOS, 2006). 
Portanto, considera-se aqui que uma das ferramentas possíveis para a promoção da educação ambiental em parques é a trilha interpretativa (TI). As trilhas interpretativas, além de propiciarem um maior contato com o ambiente natural são eficazes no processo de interação homem/natureza, colaborando na formação da consciência ambiental, promovendo, inclusive, o uso adequado da área visitada a fim de reduzir os impactos provocados pelo uso público (SIQUEIRA, 2004). Nesse sentido, a interpretação ambiental em TIs traduz-se em atividades educativas que procuram, através do contato direto com o recurso que está sendo interpretado, informar, sensibilizar, conscientizar e incentivar a capacidade de observação e reflexão. Além disso, viabiliza experiências inovadoras e aquisição de informações sobre a ecologia do local (BEDIM, 2004; LIMA, 1998; PROJETO DOCES MATAS, 2002; VASCONCELLOS, 2006).

O objetivo do presente texto é apresentar os procedimentos para estruturação de uma trilha interpretativa no Morro das Andorinhas, como ferramenta de promoção da Educação Ambiental no Parque Estadual da Serra da Tiririca. Assim, também é proposto um guia de interpretação ambiental do local.

\section{Material e métodos}

\section{Área de estudo e indicadores}

O Parque Estadual da Serra da Tiririca (PESET) foi criado pelo Governo do Estado do Rio de Janeiro através da Lei 1.901, de 29 de Novembro de 1991 e está situado na divisa dos municípios de Niterói e Maricá. Uma porção de ecossistemas marinhos também é abrangida pelo Parque, da Ponta de Itaipuaçu até 1.700 metros em direção ao mar aberto de encontro ao Costão rochoso de Itacoatiara (PIMENTEL, 2008). O PESET é a única Unidade de Conservação situada na região metropolitana do Rio de Janeiro, criada a partir da organização de movimentos comunitários (BARROS; GARCEZ, 2003) que lutaram contra as ameaças representadas pela especulação imobiliária de remanescentes da Mata Atlântica da região.

O Morro das Andorinhas foi incluído no Parque através da Lei Estadual n ${ }^{\circ} 5.079$ de 03 de Setembro de 2007 (BARROS, 2008) e localiza-se na zona urbana da Região Oceânica do município de Niterói, entre os bairros de Itaipu e Itacoatiara (PEREIRA; MELLO, 2011) (Figura 01).

Com 2,6 km de extensão, a trilha do Morro das Andorinhas atravessa a sua cumeeira e permite o acesso aos caminhos de pesca da comunidade de pescadores, finalizando em uma área de afloramento rochoso denominado Ponta das Andorinhas (BARROS; GARCEZ, 2003; BARROS et al., 2005). O seu trajeto, passa por mirantes que possibilitam a visualização da Praia de Itaipu e da Praia de Itacoatiara, e por isso recebe visitação intensa. Foi realizada uma caracterização física e biológica da trilha, a partir de indicadores e procedimentos propostos por Bayfield (1987) e Magro (1999). 


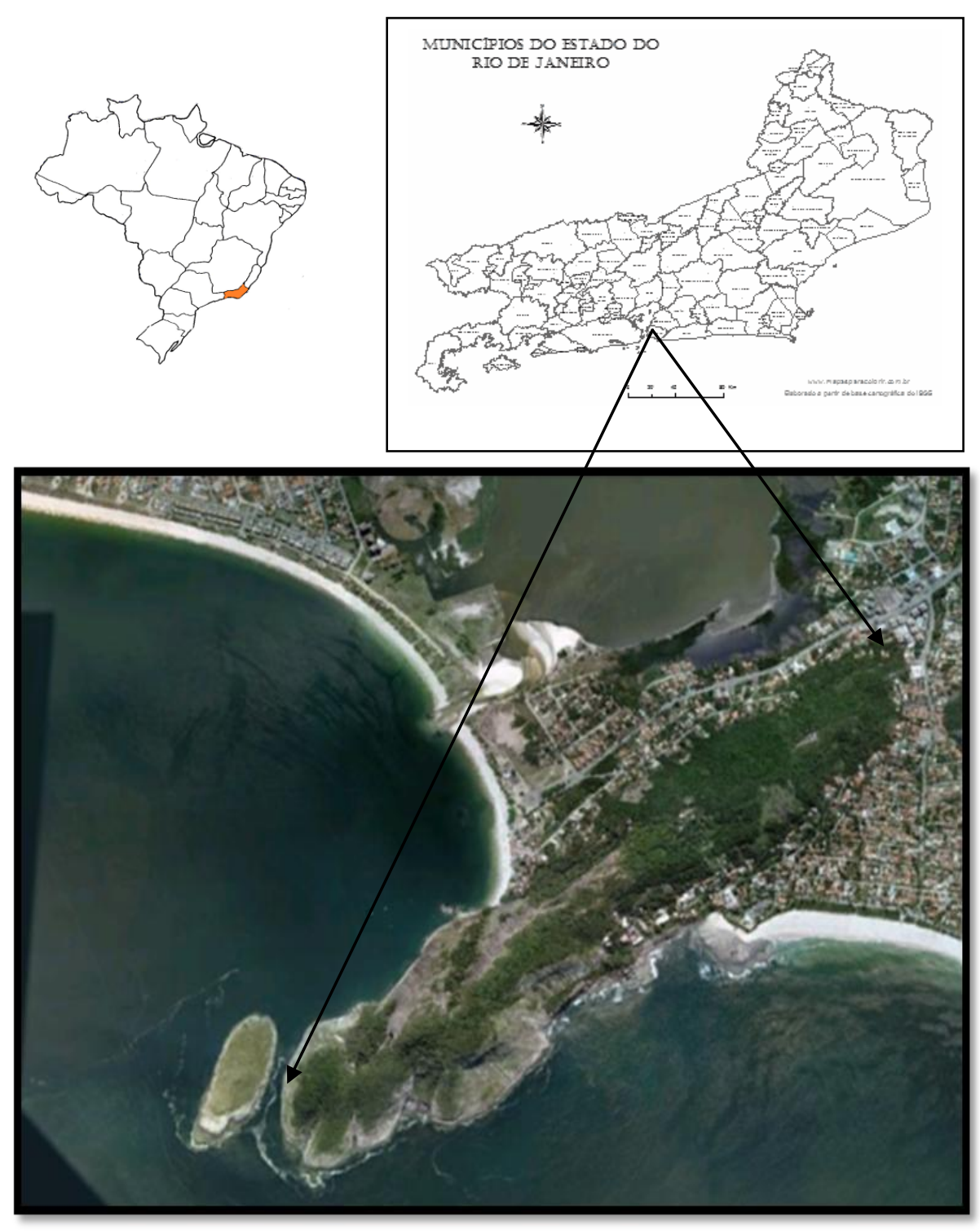

Figura 01. Morro das Andorinhas.

Fonte: Imagem Google Earth (2013)

\section{Planejamento para constituição da Trilha Interpretativa}

As primeiras reflexões a respeito da estruturação da TI e definição de possíveis pontos de parada e discussão na Trilha do Morro das Andorinhas ocorreram durante a participação no Programa de Educação Ambiental (PEA) do Museu de Arqueologia de Itaipu (MAI), através do acompanhamento das atividades em que os alunos são levados a conhecer a trilha. Foram realizadas pesquisas no tocante aos aspectos históricos, ecológicos e sociais locais e que possivelmente, quando abordados durante a interpretação, favoreceriam o processo de educação ambiental. No dia 26 de Agosto de 2012, durante uma caminhada na trilha e a partir de novas observações, seis pontos interpretativos foram consolidados. Efetivou-se não apenas a escolha dos pontos, mas também quais aspectos seriam abordados em cada um deles. Para desenvolver a atividade de interpretação foi elaborado um guia contendo orientações iniciais para a caminhada na trilha e seis pontos de parada para interpretação. 


\section{Resultados e discussão}

Foi possível perceber que a trilha está sofrendo impactos decorrentes de sua visitação, tais como: alargamento superior a um metro em quase toda extensão da trilha; alto grau de compactação do solo, que favorece o escoamento superficial da água da chuva, intensificando os processos erosivos em trechos com maior declividade. Essas informações, bem como o resultado da observação de outros indicadores ambientais devem subsidiar um programa de monitoramento dos impactos do uso na trilha do Morro das Andorinhas.

As atividades do PEA que preveem a visitação ao PESET, iniciam sempre com uma série de recomendações e orientações tanto a respeito do cuidado pessoal, como uso do filtro solar e porte de água para beber, quanto sobre comportamento durante o percurso: a importância de comportamentos específicos para não perturbar a fauna, não usar a trilha como banheiro, não deixar lixo, nem retirar nada da UC. Com isso, essas recomendações também foram inseridas no guia proposto. As atividades na trilha, relacionadas ao Museu, são realizadas com monitores. Quando a trilha interpretativa é percorrida com o auxílio de um monitor, sugere-se a existência de pontos de parada situados em locais estratégicos, que apresentem aspectos relevantes a serem abordados (ANDRADE; ROCHA, 2008). Além disso, recomenda-se que o número de paradas não seja excessivo, principalmente quando a atividade envolver crianças, que majoritariamente se dispersam com facilidade, portanto, a demora em demasia pode prejudicar o trabalho de interpretação (GUERRA, 2005).

Logo no inicio da trilha um emaranhado de fios chama a atenção dos visitantes, levando-os a questionar sobre a permissão da presença de moradores naquele local, visto que a trilha faz parte de um parque e há explicações prévias sobre as implicações legais desse fato. Esse momento era aproveitado para relatar que, no contexto da criação do PESET havia uma situação específica: a presença de uma comunidade tradicional, dentro dos seus limites. Esse assunto, também é abordado em outro ponto interpretativo, nomeado como praça do balanço.

Os aspectos biológicos abordados na trilha interpretativa dizem respeito à presença de duas espécies vegetais, uma nativa e outra exótica. A espécie nativa é uma palmeira, conhecida como Jerivá (Syagrus romanzoffiana). Apesar de que, durante as atividades do PEA, essa espécie não ter sido mencionada, inseri-la na TI é de suma importância para que os usuários do guia conheçam um pouco sobre a flora da Mata Atlântica. No que se refere à espécie exótica, a observação do sítio das jaqueiras subsidiaram a discussão sobre o processo histórico de ocupação do morro, bem como os danos que uma espécie exótica pode representar para um ecossistema.

Os últimos pontos interpretativos propostos são os mirantes de Itaipu e de Itacoatiara, onde é sugerido que o visitante observe a paisagem, atentando-se não somente para os aspectos naturais, como também os processos de intervenção humana que modificam a mesma. Além disso, do mirante de Itaipu é possível observar um sambaqui, importante sítio arqueológico, o que permite enfatizar a sua importância histórica, social e ambiental para a região.

A partir dessas observações foi estabelecido o guia para trilha interpretativa, conforme abaixo: 
Trilha Interpretativa no Morro das Andorinhas: traduzindo a linguagem do ambiente

\section{Ponto de partida}

Atente-se às orientações para garantirmos uma agradável caminhada!

- Fez uso do protetor solar? Apesar das árvores, o sol pode aparecer em determinados pontos da trilha, é bom se proteger!

- Está levando água? Você pode sentir sede durante o trajeto!

- Na floresta não tem banheiro! Lembre-se disso antes de iniciar a caminhada.

- Animais de hábitos noturnos podem estar descansando no momento em que você passar por eles, portanto, não grite na trilha! Vamos respeitálos!

- Para evitar o pisoteio nas margens da trilha, caminhe dentro dos seus limites, preferencialmente em fila indiana.

- Não retire nada do ambiente! As plantas são bonitas e ficam ainda mais no lugar que estão! Você não gostaria se the retirassem de um lugar que gosta de permanecer, certo?

- Não deixe nada por lá. Se você gerou lixo durante a caminhada, leve-o de volta e despreze-o em um local adequado.

- Caminhe sem pressa ou poderá não ter fôlego para concluir o percurso.

Agora sim, estamos prontos! Vamos lá?

Para início de conversa: $O$ que vocês esperam encontrar na trilha? 


\section{Ponto de parada 1: Fios para todo o lado!}

Observe a fiação no início da trilha. Entrou em choque? Por que motivo esses fios estão dispostos dessa maneira? Lembre-se: você está no interior de um Parque! Isso é permitido? Não se esqueça: lá em cima existem moradores de uma comunidade tradicional!

\section{Ponto de parada 2: Palmeira Jerivá}

Olhe só, uma espécie nativa da Mata Atlântica, no meio da trilha! Nativa? Como assim? Uma espécie nativa é aquela que habita de forma natural a região em que vive, ou seja, ela é própria daquele ambiente. Esta palmeira chamada Jerivá apresenta esta característica.

\section{Ponto de parada 3: Praça do balanço!}

Observe com atenção! Como você descreveria esse ambiente?

Você acredita que as pessoas que aqui residem valorizam a natureza? $E$ por falar em residência, isso é permitido dentro de um Parque? Mas essas pessoas constituem uma comunidade tradicional. E o que isso tem a ver? Podemos falar em impactos ao relacionarmos essas pessoas ao Parque?

\section{Ponto de parada 4: Jaqueira à vista!}

Você sabia que as Jaqueiras são espécies exóticas? E você sabe o que é isso? As espécies exóticas são aquelas estabelecidas em territórios onde não são naturalmente encontradas. A presença de uma espécie exótica em determinado ambiente pode acarretar quebra no equilibrio ecológico, uma vez que a competição por água, luz do sol e nutrientes pode resultar no desaparecimento das espécies nativas.

Você consegue perceber esse efeito no ambiente em que observa?

\section{Ponto de parada 5: No mirante de Itacoatiara}

Fique à vontade para admirar essa paisagem espetacular, utilize os binóculos para aprimorar sua visão! Agora reflita: será que esse ambiente sempre foi 
assim? Como você imagina essa paisagem daqui a alguns anos? Como você imagina a paisagem no passado.

\section{Ponto de parada 6: No mirante de Itaipu}

Observe a orla da praia. Onde é possivel perceber a intervenção humana? Você consegue imaginar este ambiente sem essa influência? Como seria?

E a duna? Você a observou? As dunas são formadas pelos ventos vindos do mar que carregam areia fina. Essa areia é estabilizada por uma vegetação que desempenha um importante papel na sua fixação. As dunas são protegidas por lei e é considerado crime ambiental a destruição da vegetação, portanto, este não é o local apropriado para passear de automotores, certo? Se nos aproximarmos da duna perceberemos que existe uma grande quantidade de carapaças de conchas, lascas de pedras e até mesmo restos de ossos de animais. Estamos diante de um sítio arqueológico. Os vestígios que encontramos caracterizam o modo de vida dos antigos ocupantes que desenvolviam atividades coletoras e caçadoras e construíam os chamados sambaquis, que são um amontoado de conchas.

Está vendo a laguna? A laguna de Itaipu já foi uma lagoa. Ué, mas existe diferença? Sim, a água de uma lagoa não é salgada, já uma laguna apresenta uma variação de salinidade. Observe com atenção! Que motivo levou a lagoa ter se tornado laguna? O homem interveio de modo a promover essa diferença?

\section{Para finalizar: as suas expectativas sobre a trilha se confirmaram?}

\section{Considerações finais}

O fato da visita ao PESET proporcionar uma vista exuberante, os olhares dos usuários em relação às trilhas, muitas vezes, voltam-se somente para a sua beleza cênica, observada através dos mirantes existentes no Parque, não se atentando para os interessantes aspectos ecológicos e sociais do próprio ambiente visitado. Através da trilha interpretativa os visitantes percebem aspectos que não haviam percebido anteriormente. Portanto, é importante que se aproveite as atividades de incursão à trilha para se chamar a atenção não só para os aspectos "macros", como a paisagem e os processos que a transformaram ao longo do tempo, mas 
também para os detalhes existentes no interior do Parque, a fim de estimular a sensibilização ambiental e o respeito pela natureza.

As trilhas interpretativas podem ser o caminho para a mitigação dos impactos causados pelo uso público, pois tem alto potencial para despertar a mudança de valores nos indivíduos, a compreensão crítica em relação ao ambiente natural e promoção de atitudes para a conservação ambiental.

\section{Referências bibliográficas}

ALCANTARA, L.C. Trilhas interpretativas da natureza: Planejamento, Implantação e Manejo. 2007. 87p. Monografia (Especialização em Turismo e Desenvolvimento Sustentável) - Universidade de Brasília, Centro de Excelência em Turismo, Brasília. Disponível em:< http://bdm.bce.unb.br/bitstream/10483/194/1/2007_LeonardoCintraAlcantara.pdf. > Acesso em: 19 nov. 2012.

ANDRADE, W.J.; ROCHA, R.F. Manejo de trilhas: um manual para gestores. Instituto Florestal, São Paulo, 2008. Disponível em: <

http://www.iflorestal.sp.gov.br/publicacoes/serie_registros/Revistas_completas/IFSR35.pdf.> Acesso em: 20 mar. 2013.

BARROS, A. A. Análise florística e estrutural do Parque Estadual da Serra da Tiririca, Niterói/Maricá, Rio de Janeiro, Brasil. 2008. 218 p. Tese (Doutorado em Botânica) Escola Nacional de Botânica, Instituto de Pesquisa Jardim Botânico do Rio de Janeiro. Disponível em:

<http://urutau.proderj.rj.gov.br/inea_imagens/downloads/pesquisas/PE_Serra_da_Tiririca/Bar ros_2008.pdf.> Acesso em: 27 ago. 2012.

BARROS, A. A.; GARCEZ, C. Atividades de educação ambiental na recuperação da vegetação do Morro das Andorinhas, Niterói/ RJ. In: ENCONTRO REGIONAL DE ENSINO DE BIOLOGIA, 2., 2003, Sâo Gonçalo/RJ. Anais... São Gonçalo, SBENBI; UERJ/FFP, 2003. P. 110-114.

BARROS, A. A.; LAURINDO, T. F. S.; SILVEIRA, R. M.; MENDONÇA, N. C.; PINTO, L. J. S.; GARCEZ, C. Comunidades Tradicionais e Universidade: Prática de educação ambiental no Morro das Andorinhas, Niterói, RJ. In: ENCONTRO REGIONAL DE ENSINO DE BIOLOGIA, 4., 2005, Rio de Janeiro. Anais... Rio de Janeiro, SBENBIO; UFRJ, 2005. P. 495-499.

BEDIM, B. P. Trilhas interpretativas como instrumento pedagógico para a educação biológica e ambiental: reflexões. 2004. Disponível em: http://www.ldes.unige.ch/bioEd/2004/pdf/bedim.pdf. Acesso em: 14 nov. 2012.

BAYFIELD, N. G. Approaches to reinstatement of damaged footpaths in the Three Peaks area of the Yorkshire Dales National Park. In: AGRICULTURE AND CONSERVATION IN THE HILLS AND UPLANDS. ITE, 23., 1987, Symposium... 1987, P. 78-87.

BRASIL. LEI N. ${ }^{\circ} 9.985$, de 18 de Julho de 2000. Decreto N. ${ }^{\circ} 4.940$, de 22 de Agosto de 2002. Institui o Sistema Nacional de Unidades de Conservação da Natureza (SNUC). Brasília: IBAMA, Diretoria de Ecossistemas, 2002. 35 p.

BUENO, F.P. Vivências com a natureza: uma proposta de Educação Ambiental para o uso público em Unidades de Conservação. Revista Brasileira de Ecoturismo, São Paulo, v.3, n.1, p. 61-78, 2010. Disponível em: 
http://www.sbecotur.org.br/rbecotur/seer/index.php/ecoturismo/article/view/77/28. Acesso em: 25 out. 2012.

\section{GARCEZ, C. S. Educação Ambiental e Ecologismo nas Trilhas das Caminhadas}

Ecológicas. 2007. 136 p. Dissertação (Mestrado em Ciência Ambiental)- Depto. de Geociências, Universidade Federal Fluminense, Niterói, 2007.

GUERRA, A. Proposta de Trilha Interpretativa guiada para a Mata "Vista Chinesa" da SOEICOM - Lagoa Santa/Vespasiano. In: ENCONTRO DE GEÓGRAFOS DA AMÉRICA LATINA, 10., 2005, São Paulo. Anais... São Paulo, Universidade de São Paulo, 2005. Disponível em:

http://observatoriogeograficoamericalatina.org.mx/egal10/Teoriaymetodo/Metodologicos/05.p df. Acesso em: 25 mar. 2013.

IRVING, M. A. (Org.). Áreas protegidas e inclusão social: construindo novos significados. Rio de Janeiro: Aquarius, 2006.

LIMA, S. T. Trilhas Interpretativas: a aventura de conhecer a paisagem, Cadernos Paisagem. Rio Claro, UNESP, n. 3, p. 39-44, 1998. Disponível em:

<http://www.repams.org.br/downloads/Lima,\%20Solange.pdf. $>$ Acesso em: 19 nov. 2012.

LOBO, A. C.; SIMÕES, L. L. Manual de Monitoramento e Gestão dos Impactos da Visitação em Unidades de Conservação. São Paulo: Secretaria de Meio Ambiente de São Paulo, 2009.

MACHADO, R. Proposições Conservadora e Crítica em Educação Ambiental: a discussão das duas possibilidades em um mesmo espaço. Revista Brasileira de Ecoturismo, São Paulo, v.3, n. 1, p. 23-46, 2010. Disponível em:

http://www.sbecotur.org.br/rbecotur/seer/index.php/ecoturismo/article/viewFile/697/343\#pag $\underline{\mathrm{e}=61}$. Acesso em: 21 out. 2012.

MAGRO, T.C. Impactos do uso público em uma trilha no Planalto do Parque Nacional de Itatiaia. 1999. 135p. Tese (Doutorado em Engenharia Florestal) - Escola de Engenharia de São Carlos. Universidade de São Paulo, São Carlos, 1999.

MEDEIROS, R. Evolução das tipologias e categorias de áreas protegidas no Brasil. Revista Ambiente e Sociedade. v. 9, n. 1, 2006. Disponível em:

<http://www.scielo.br/pdf/asoc/v9n1/a03v9n1.pdf.> Acesso em: 17 ago. 2012.

MEDEIROS, R.; IRVING, M.; GARAY, I. A proteção da natureza no Brasil: evolução e conflitos de um modelo em construção. RDE. Revista de Desenvolvimento Econômico, ano 6, n. 5, p. 83-93. Disponível em:

<http://revistas.unifacs.br/index.php/rde/article/viewFile/115/119>. Acesso em: 4 dez. 2013.

MENGHINI, F,B.; GUERRA, A.F.S. Trilhas interpretativas : caminhos para a educação ambiental. ANPEd Sul. Itajaí, SC, 2008. Disponível em:

<http://www.portalanpedsul.com.br/admin/uploads/2008/Educacao_ambiental/Trabalho/05_0 8_12_Trilhas_interpretativas_caminhos_para_a_educacao_ambiental.pdf $>$. Acesso em: 17 ago. 2012.

OLIVEIRA, L. R. N. (Org). Unidades de conservação da natureza. São Paulo, 2009. n.3.

Cadernos de Educação Ambiental. São Paulo, Governo do Estado de São Paulo; Secretaria do Meio Ambiente; Fundação Florestal, n. 3, 2009. Disponível em:<

http://www.ambiente.sp.gov.br/wp-content/uploads/publicacoes/sma/unidConservNat.pdf>. Acesso em: 10 nov. 2012. 
OLIVEIRA, R. T.; BLOOMFIELD, V. K.; MAGALHÃES,L. M. S. Trilha auto-guiada: proposta deimplantação e interpretação na FlorestaNacional Mário Xavier Sandra Regina da Costa. Floresta e Ambiente, v. 6, n. 1, p. 138-143, 1999. Disponível em: < http://www.geocities.ws/floramrural/p0138.pdf. > Acesso em: 26 nov. 2012.

PEREIRA, M. C. B.; MELLO, Y. R. Projetos globais e resistências locais: pescadores artesanais e Unidades de Conservação no litoral, Rio de Janeiro - Brasil. Desenvolvimento e Meio Ambiente, n. 24, p. 137-150, jul./dez. 2011. Disponível em: < http://ojs.c3sl.ufpr.br/ojs2/index.php/made/article/view/21604/17085. > Acesso em: 19 nov. 2012.

PIMENTEL, D. S. Os parques de papel e o papel social dos parques. 2008. 254p. Tese (Doutorado em Recursos Florestais) - Escola Superior de Agricultura Luiz de Queiroz, Piracicaba, Universidade de São Paulo, 2008.

PIMENTEL, D. S.; MAGRO, T. C. Múltiplos olhares, muitas imagens: o manejo de parques com base na complexidade social. GEOgraphia (UFF), v. 13, p. 92-113, 2011.

PROJETO DOCES MATAS. Manual de Introdução à Interpretação Ambiental. Projeto Doces Matas/ Grupo Temático de Interpretação Ambiental. Belo Horizonte, 2002. Disponível em:

<http://www.ief.mg.gov.br/index.php?option=com_content\&task=view\&id=79\&Itemid=94. $>$ Acesso em: 14 nov. 2012.

SILVA, N.P.S.; NETO, A.R.C. A Educação Ambiental como Instrumento de Sensibilização Turística em Unidades de Conservação. Revista Eletrônica Aboré , 2007. Disponível em: <http://www.revistas.uea.edu.br/old/abore/comunicacao/comunicacao_pesq_3/Nathalin\%20Pr iscila\%20de\%20Souza\%20da\%20Silva.pdf. > Acesso em: 10 nov. 2012.

SIQUEIRA, L. F. Trilhas interpretativas: Uma vertente responsável do (eco) turismo. Caderno Virtual de turismo, n. 14, 2004. Disponível em: < http://www.ivtrj.net/caderno/anteriores/14/siqueira/siqueira.pdf.> Acesso em: 14 nov. 2012.

TAKAHASHI, L.Y. Caracterização dos Visitantes, suas preferências e percepções e avaliação dos impactos da visitação pública em duas unidades de conservação do Estado do Paraná. 1998. Tese (Doutorado em Ciências Florestais) - Curso de Pós-graduação em Engenharia Florestal, Setor De Ciências Agrárias, Curitiba, Universidade Federal do Paraná. 1998. Disponível em: <http://dspace.c3sl.ufpr.br/dspace/bitstream/handle/1884/26783/T\%20\%20TAKAHASHI,\%20LEIDE\%20YASSUCO.pdf?sequence=1>. Acesso em: 9 set. 2012.

TILDEN, F. Selecciones de "Interpretando Nuestra Herencia”. Turrialba, Costa Rica: CATIE, 1977.

VASCONCELLOS, J. M. de O. Educação e Interpretação Ambiental em Unidades de Conservação. Fundação O Boticário de Proteção à Natureza. Cadernos de Conservação, ano 3, n. 4, dez. 2006. 